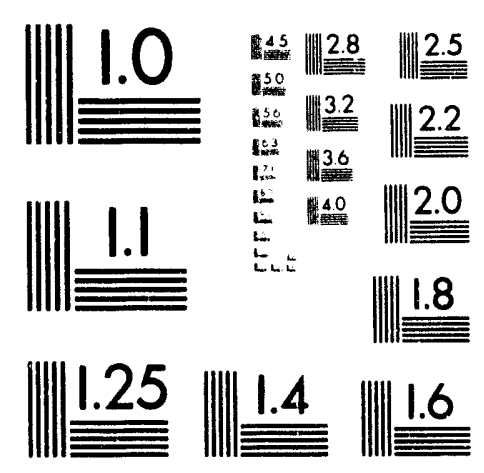



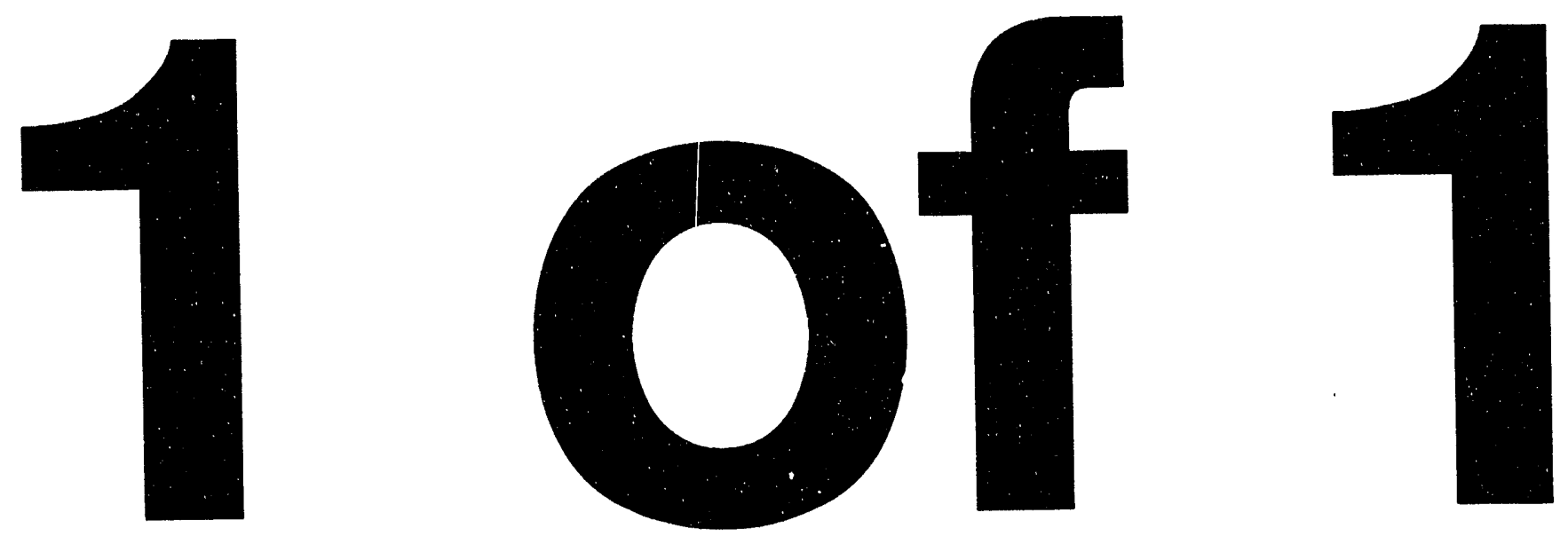
PNL-SA-22358

\section{LESSONS LEARNED IN PROCURING A LASER OPTICAL DISK SYSTEM}

V. L. Berndt

May 1993

\section{DISCLAIMER}

This report was prepared as an account of work sponsored by an agency of the United States Government. Neither the United States Government nor any agency thereof, nor any of their employees, makes any warranty, express or implied, or assumes any legal liability or responsibility for the accuracy, completeness, or usefulness of any information, apparatus, product, or process disclosed, or represents that its use would not infringe privately owned rights. Reference herein to any specific commercial product, process, or service by trade name, trademark, manufacturer, or otherwise does not necessarily constitute or imply its endorsement, recommendation, or favoring by the United States Government or any agency thereof. The views and opinions of authors expressed herein do not necessarily state or reflect those of the United States Government or any agency thereof.

Presented at the

Monthly Meeting of Bellevue

Eastside Chapter of Association

of Records Managers and Administration

May 11, 1993

Bellevue, Washington

Prepared for

the U.S. Department of Energy

Contract DE-AC06-76RLO 1830

Pacific Northwest Laboratory

Richland, Washington 99352 


\section{LESSONS LEARNED IN PROCURING A LASER OPTICAL DISK SYSTEM}

\section{INTRODUCTION}

In the beginning, there was stone and later papyrus. Quill pens were used to record important facts and events on handcrafted papers of various qualities. Fast forward to the 20th century to mass-produced paper, copy machines, microfilm, microfiche, and computer mag tape and floppy and hard disks for storing and controlling records. More recent arrivals include the compact disk (CD), laser optical disk, and other state-of-the-art technologies for storing and managing records and information electronically.

I am here to tell you about one records program that defined how its needs could be best supported by current technology and how the appropriate system was designed and procured, with many lessons learned along the way.

\section{BACKGROUND}

I am associated with the Hanford Radiological Records Program that maintains the occupational radiation exposure records for the U.S. Department of Energy (DOE) at the Hanford Site. The site has evolved through many changes during its 45 -year operating history, but the responsibility for administering and maintaining the dosimetry records has remained a centralized function under the same organization. The records have a 75 -year retention schedule. Since the early 1940s, the record-keeping system has progressed from a strictly paper system to first one that combined paper and micrographics fiche; and then to a computer-assisted retrieval (CAR) micrographics system.

In 1982 we had barely gotten the CAR system off the ground, when we became aware of laser optical disk (LOD) technology. LOD represented an upcoming technology that introduced such terms as "electronic document control" and "electronic imaging," which held great promise for application under our records program because of its ability to store both computer data and 
digitized images on the same system, its high-quality print-outs, and its stability (it doesn't accidentally erase and it isn't susceptible to headcrashes).

In 1989 we were advised that the existing UNIVAC computer would no longer be available and our database would be migrating to an IBM Large Scale Informatic n System (LSIS) computer. Because our records database would need to be redeveloped to accommodate this change in mainframe computers, a project team was organized. The team included record management staff, database design experts, and computer services personnel.

One result of the database redevelopment effort was the reduction of the amount of paper coming through to be microfilmed, indexed, and subsequently stored. To record changes to the database, it was decided that an electronic transaction log would be designed into the new database. Changes recorded would include who made the changes, the data and time of the changes, the types of changes, the data in the changed field before and after the changes, and the identifiers of the individual whose record was changed. This electronic transaction log would take the place of changes previously made on paper. Incorporation of the electronic transaction log prompted the need to store the electronic records in a cost-effective and timely manner.

Electronic changes would accumulate and increase storage costs on the mainframe if they were left on it for long periods. The ability to download to a PC-based system and then to optical disk was the logical choice. If we were going to use the optical disk technology for the computer records, it was would also be feasible to use the technology for the paper records. The electronic imaging system would reduce the need for repetitive handling of the paper records that could not be reduced to electronic form. Thus the new LOD technology's ability to store both images and data on non-erasable disks (Write Once Read Many [WORM]) and its ability to readily retrieve the data were advantages that needed to be carefully considered.

As project manager, I assumed responsibility for researching LOD technology to determine the feasibility of incorporating an electronic imaging system to support and enhance our occupational radiation exposure record-keeping services at Hanford. A feasibility study, the first 
step in the procurement process, was followed by a requirements analysis, definition of purchase specifications, the bidding process, vendor selection, and system design, implementation, and acceptance testing. As you will soon learn, I gained insights and learned lessons every step of the way.

\section{FEASIBILITY STUDY}

The feasibility study was largely a matter of researching and docu nenting the rapidly changing record-keeping media and technologies to determine their applicability for upgrading our records system. Documentation was critical in selling the new technology to management and in justifying the procurement of expensive equipment.

Initially, one of the most helpful sources of information was the annual conferences of the Association of Records Managers and Administrators (ARMA) and the Association of Information and Image Management (AIIM). I attended conference seminars presented by knowledgeable people and saw the latest products at the conference vendor shows. I interviewed vendors to get answers to my long list of questions, such as hardware requirements, capacities of disks, costs, etc. I found out who were potential users of the new technology and called them to "pick their brains." I also absorbed information from many articles in the trade journals and newsletters.

I researched our options for nearly two and a-half years, before formalizing my findings in a feasibility study report. The report described the existing systems and their limitations, as well as the proposed new technology. The advantages and disadvantages of the new technology were compared with our existing CAR system. For instance going from a system that indexed sets of records to one that indexes every single document would involve longer indexing time up front. However, the ability to accurately retrieve each individual record would be much faster. The study defined any special needs (including addressing records legality issues), and provided a cost analysis, conclusions, and recommendations. 


\section{Special Needs}

In responding to the proposed change in mainframe computers, we wanted to make sure that we had the most efficient records system possible using the best applicable current technology. Basically, we needed the new system to be able to store both electronic transaction records and hard-copy documents; to interface in real time with the mainframe computer database for validating the indexing criteria; and to be expandable for future growth or changes. Most systems I was reading about were stand-alone systems that did not require this interaction. I quoted articles from various records and information management sources to emphasize the importance of this requirement, I also described the capabilities, functions, hardware, and how the new system would interact with the existing system.

Even though our existing micrographics CAR system had served us well for over 10 years, the redevelopment of the database afforded us the opportunity to assess our situation and to look at newer technologies. The redevelopment would allow us the opportunity to store the index of an imaging system on the hard disk of the system, and not add to storage costs on the mainframe computer. It would also allow for faster retrieval and for better copies of documents when needed.

One major area of concern was the legality of the electronic records that would replace the hard-copy records. I quoted Donald Skupsky, noted legal authority in our field, whenever I could. I also referred to Robert Williams' Legality of Microfilm (Williams 1984), which addresses future technology, and Williams' article called "Are Optically Stored Records Legal?" (Williams 1988).

\section{System Cost}

Finally, cost was a major factor that was difficult to assess. A direct comparison of current system costs with proposed system costs showed 1) a reduction in staff, 2) the elimination of microfilm and Computer Output Microfilm (COM) costs, and 3) a significantly lower 
equipment cost than what the actual bottom line showed. Although the new system would require more indexing time up front, the record retrieval time and accuracy would be greatly enhanced in the long run. It was difficult to attach a dollar figure to these operational elements for purposes of cost/benefit analysis and system comparison. Certainly, in the case of litigation, the inability to retrieve even one document can cost hundreds of thousands of dollars. A $\$ 100,000$ system could be considered good insurance in a case like that. Still, it is not easy to assign dollar amounts to intangibles like system credibility and integrity.

\section{REQUIREMENTS ANALYSIS}

After completing the feasibility study, I worked with other project team members to define the objectives and basic requirements of the imaging system we needed and why we were looking at new technologies. We defined the requirements for what we expected the system to consist of or accomplish, including key features that represented our minimum requirements. Because electronic transactions were a new concept for us and one of the primary reasons why we chose the new technology, we also identified what we understood the procedure to be for handling hardcopy documents. This process helped us plan for as many development details as we could as we entered new technological territory.

In addition to identifying the goals and objectives of the proposed system, the requirements analysis document included a Problem Statement, which identified a problem that needed to be corrected. In our case, knowing that certain hard-copy records that would be replaced by electronic transactions, we needed to know how we would best store the records for 75 years and be able to retrieve them. In our opinion, the vulnerability of magnetic disks, computer heads, and other weaknesses associated with computers made these standard storage media unacceptable. Also, the rate at which these electronic transactions would grow made it essential that they not be stored on the mainframe computer for long periods, because of the associated storage costs. 
The requirements analysis document also identified the lack of onsite capability to produce 16-mm microfilm, which could be used in the existing CAR system. (Sending the electronic transactions ofîsite for COM was not feasible due to inconvenience, cost, and vulnerability of the medium.) Tthe objectives and goals of the proposed system were identified, and the effects of implementing a new system and the effects of not implementing a new system were addressed. Budgetary and security constraints, assumptions, options, storage of unindexed data, user interface, system interface, audits, testing and acceptance criteria, training and user documentation, reliability/recovery, and sofiware documentation were also discussed.

\section{WRITING THE PURCHASE SPECIFICATIONS}

Writing the purchase specifications for the proposed system proved to be the most challenging task of the procurement process. I had no previous experience in writing specifications for the purchase of such a large and complex system. Further, because of our emerging, but still limited, knowledge of the full scope of LOD technological applications and because of the large purchase price, I worried about purchasing a system that did not meet our needs. I had heard horror stories about companies that purchased systems without enough advance research and ended up with expensive systems that could not be used.

Despite the definition provided in the detailed requirements analysis, we had problems achieving a uniform and tangible understanding of what exactly we wanted to accomplish by incorporating the new system. Achieving consensus on our system objectives between the program manager, people redesigning the database, and others involved in the program sometimes seemed out of reach. This introduced an additional hurdle in preparing to write the specifications.

Before sitting down to write, I contacted a buyer for our company for spec-writing guidance. She recommended terminology and specific clauses or phrases to use or avoid. The buyer also placed an ad in the Commerce Business Daily to see what kind of response we would get when we issued our request for proposals. We had over 50 responses! 
I also contacted an information systems expert who had helped procure imaging systems for other groups in my company. He was helpful in identifying some concerns that we needed to consider, such as backup needs, software requirements, and hardware requirements. Although he provided copies of a purchase requisition and specifications for two other imaging systems at our company, they were of little value to us because they were for vastly different applications.

Finally, I started to write the specifications, trying to identify what we needed the system to do, not how to do it. I had documented everything I could about what I thought I wanted the system to do and this helped immensely. It also helped from the start to have thoroughly discussed plans with the system users (two clerks) to maintain open dialog about various features and how they would or wouldn't work for us.

Another thing that helped me in writing the specifications was visiting two different sites that had already installed imaging systems. Although neither system was using the exact application we required, it was helpful to talk to system users and get answers to specific questions. It also helped to see how they arranged their work stations and what the disk drives and disks actually looked like.

Then came a stroke of good luck! At a meeting with some of the computer people working on the redesign of the database, someone introduced a set of overheads from a conference session on procurement of an imaging system. From the overheads I derived the name and address of the presenter, who happened to work at another DOE site. I contacted him for help.

He agreed to review the specs I had written up to that point, and he also agreed to send me a copy of the specs he had used to procure an imaging system. After reviewing my draft specs, he called to say that my specs lacked sufficient detail to ensure that 1) the vendor would understand what we needed, and 2) we would subsequently get the desired product that would perform as specified. When I received his specs, I understood his concern -- his document was 33 pages long with reduced typing, whereas my draft was under 6 pages at that point! 
We discussed the specifications several times on the phone and he was extremely helpful in explaining particular specs and why they were needed, asking me questions to further understand my needs, and in sparing me some of the mistakes he had made. Although many of the items in his specs did not apply to my application, they opened my eyes to areas I had not considered writing about. I also adopted his approach to numbering each item in the spec so that readers could easily understand and discuss the specs over the phone (i.e., 1.0, 1.1, 1.1.1, 2.0, etc.). Another important part included in the purchase specifications was called "acceptance". This section listed specific criteria that must be met for the system to be accepted.

In broadening my approach to writing more detailed specifications I consulted numerous contributors to gain a better understanding of how to best represent their interests in developing the specifications. I had to learn new terminology or consult experts who could speak "computerese." Because of our need to interface with the mainframe computer, I had to learn who to contact within the computer services group, and when to contact them. In the meantime, the design team was designing the new database, with which we would interface, and they had a different set of priorities. Because we were not sure who exactly we should be talking to regarding the interface, we convened a meeting with computer communications services staff. They provided appropriate phrases and recommended information for inclusion in the specifications to help ensure that the vendors would clearly understand our particular needs. Some of their questions caused me to dig for more information, thus continuing my cycle of learning more about what we were trying to accomplish.

Once the specs were completed, the buyer selected about 50 of the respondents and mailed them copies of our Request for Proposal (RFP).

\section{VENDOR SELECTION}

There had been so much interest in our ad in Commerce Business Daily that I anticipated a similar response to the RFP. Surprisingly, after the tremendous initial interest from 
vendors, most of whom were on the east coast or in California, only the two specific vendors I had been dealing with actually sent in bid proposals. Both of these vendors were from the Seattle area.

To prepare for the vendor selection process, I developed acceptance criteria against which to evaluate the vendor responses. I compared each vendor's bid proposal with the acceptance criteria to evaluate which system best matched our needs. Whenever I needed clarification on specific items, I called my buyer and she gave me permission to talk directly to the vendors on the specific issues.

Even though I had been in constant contact with both vendors for the preceding year or two, one stated they could not deliver certain features I needed without modifying their product, which also contained many features that we did not need. The modification would, of course, take more time and money. In final analysis, one vendor was offering to custom build exactly what we needed to make the system work for our specific needs, and the other one had an off-the-shelf product that would require modification to enable it to do what we needed. The additional unspecified time and money required to modify the off-the-shelf item made it clear that we should select the vendor that agreed to deliver the custom-designed product. In final analysis the customdesigned product also cost less.

\section{SYSTEM DESIGN}

After vendor selection we moved into the system design phase. Now our expectations and system definition had to be completely clear to ensure uniform understanding by all parties involved so that deadlines for delivery and implementation would be met. Fortunately, the in-state vendor was close enough for onsite visits, beginning with a sit-down meeting soon after the selection had been formalized. At this meeting we explained as much as we could about what we were doing under our records program and what we hoped to achieve with the new system. We also had as many development team members and system users at the meeting as possible so that 
everyone could meet one another. This was important because much of our communication would be over the phone, and we wanted people to feel that they knew one another and who to call to discuss and resolve problems.

To streamline communication about general system concerns, we established single points of contact within our program and at the vendor company. We also established guidelines for how and when to contact other team members to discuss more specific topics within their fields of expertise. For instance, even though I was the project manager, it was sometimes more effective for the vendor to talk directly with the computer people about communications or interfaces. In such cases, the team members always kept me informed of their communication with the vendor.

I also made a habit of documenting phone conversations during which decisions were made or questions were raised that needed action (and by whom). I distributed copies of the documentation to all involved parties and filed one record copy.

The vendor was the primary player in the system design. Based upon his understanding of our needs, he designed screens, planned the interface with the mainframe computer and wrote the software to make it happen. He designed the flow and arrangement of screens and built in the edits he deemed necessary. He communicated with the computer staff who were designing the database and with the computer communication staff who work with the mainframe and would control our interface.

\section{SYSTEM IMPLEMENTATION AND TESTING AND USER TRAINING}

Implementation of the new system involved installation of hardware and software, making connections, system testing, and user training. The system hardware (including computer hard disk, monitor and keyboard, scanner, optical disk drives, laser printer, and uninterrupted power supply) had to be physically set up. Previous arrangements for direct cable installations had to be made to achieve immediate communications with the mainframe and a Local Area Network 
(LAN) drop for possible future communications. Testing of these communication links had to be coordinated with the design team of the new database and the computer communications siaff.

Because of the custom-designed software for this system and the real-time interfacing with the mainframe computer, the vendor had to test what he had designed and developed. (Testing from the user viewpoint was completed later). The vendor first demonstrated screens and how to move through the system, and then let the clerks operate the system while he observed them. This observation period provided an opportunity for the clerks to comment on what worked well and what didn't. It gave the vendor a $c_{n}$, to learn more about why they needed certain features and why they didn't need others Screens wert -earranged in some instances to make them more efficient.

Fortunately the design team for the new database had converted some real data from the existing database and moved it to the new mainframe as a "test database." The design team used the test database in finalizing their work. The clerical staff used the test database to test procedures and to do actual validation of indexing criteria. The design team's use of the test database affected our use of it at times, but the test database did give us an opportunity to test the validation process.

During system testing, the testing of the electronic transaction logs was most difficult, becaus; no real electronic transactions would be made until the new database was operational (in early April 1993). So we had no real data to download, archive, and retrieve as a test exercise. However, there was a limited amount of test data that could at least sk.uiv us what a transaction looked like so we were able to test downloading and print out of the data.

Training was also conducted during the implementation phase. This allowed the vendor to further observe how the clerks worked with the documents and to start evaluating the screens he had designed. Many changes were made the first week in screen arrangement and design, and some messages that appeared on the screen that were not needed were eliminated. 
The veis Jor provided a helpful procedures notehook for the most basic start-up procedures. This notebook will provide the basis for subsequent development of our in-depth desk procedures.

\section{ACCEPTANCE TESTING BY THE CUSTOMER}

A 30-day acceptance testing period was written into the purchase specifications to allow for adequate acceptance testing time and to ensure that the vendor was paid within a reasonable time frame. Specific acceptance testing criteria were itemized in the specifications. During the 30-day period we tried to "break the system." Even with acceptance test criteria, it was difficult to adequately test the system. The new system represented an extremely different way of operating and we ran into problems that we could not have anticipated. For instance, we received error messages that we did not understand and had to resolve via phone calls to the vendor. Equipment malfunctions aiso required phone calls to the vendor.

We wanted to know what would or would not work. We put every conceivable record situation we might encounter through the system. This included things such as indexing one document to multiple indices, scanning and indexing two-sided documents and multi-page documents, adjusting the settings of the scanner to accommodate different paper sizes and lightness and darkness densities, retrieving scanned and indexed images, and retrieving electronic records.

Open communication with the vendor during this period was very important. Having a vendor who has been very responsive and has really listened to us when we've encountered problems has been extremely beneficial. On many occasions he has walked the clerks through problem resolution over the phone. He has made numerous onsite visits to work out the various stages of implementation.

Any problems that would prevent us from accepting the system as specified were called in to the vendor, with a follow-up letter detailing the problems and the expected resolution. Final 
acceptance of the system was documonted in a report, and a letter was written to the vendor, with a copy to the buyer, saying we had tested and accepted the system -- so that there was no question about the acceptability of the system.

We have been working with the system since early January 1993, and we are already developing a list of ideas for future implementation. The vendor has been very helpful in suggesting system enhancements and expansion opportunities.

\section{LESSONS LEARNED}

As stattd previously, I gained insights and learned lessons throughout the process of procuring our new imaging system. Some specific lessons learned during the procurement process are summarized in the following sections to help others who might be contemplating the acquisition of imaging technology. Looking back over the last couple of years and the process we have come through, two recommendations stand out for consideration at the very beginning of the process: 1) know and completely define your objectives, and 2) very early in the process involve those individuals who will use the system when it is all installed.

\section{FEASIBILITY STUDY}

Trying to write a feasibility study on something as new as this technology proved to be difficult. Hindsight has shown that many of the claims made by articles and vendors simply do not hold true in the real work area. For example, requiring a particular scanning time seems like a reasonable specification. In reality, the many different types of documents and different sizes do not allow uniform scanning. Different paper weights, originals versus copies, and several other factors affect scanning time. Because ooff the reduced need to handle the paper, my feasibility study indicated that by incorporating LOD technology we could reduce staff. This may be true over the long-term, but the new system is currently taking more staff time. This is partly because 
we have a records backlog, but also because the scanning and indexing processes are slower than we knew when I wrote the feasibility study.

The justification of system cost is another area that remains largely ill-defined. You can estimate what an imaging system will cost to develop and implement, but until you define actual needs, some of which evolve during the procurement process, you don't really know how to estimate the cost.

\section{REQUIREMENTS ANALYSIS}

During the requirements analysis phase I learned that I was trying too hard to sell this technology by including every kind of record we had in the three different records systems under our program. We eventually decided to concentrate on our primary occupational radiation exposure record system to get a basic understanding of how the new technology would work before considering the same for the other two systems. This has proven to be a wise decision, because the new system is taking so much time to learn and to catch-up on the backlog, that trying to learn new systems for the other records types we maintain would complicate and add to the magnitude of the daily workflow. Using the current system for some time will help us know and understand what we will need for the other records.

\section{PURCHASE SPECIFICATIONS}

When writing the purchase specifications, the most important lesson I learned was not to assume anything -- put everything down in writing. Although vendors would tell me they could do what I wanted, I soon realized that my specifications had to be detailed to define exactly what I expected them to deliver.

It was also important to define a well-organized and logical outline for the specification document, numbering each heading and line item. The numbering system was particularly helpful 
when discussing the document with others (especially over the phone or in writing), because it ensured that we were both discussing the same item.

When interacting with groups or functions outside of the project organization (such as we were with the mainframe interface design team), it is important to make early contact and maintain open channels of communication throughout the process. Lack of knowledge in this area resulted in some of these contacts being made later than preferred. I learned to ask questions of all parties to find out what they needed to know. I reminded them that I didn't know what they needed, so they needed to be explicit in defining their needs. I asked about hardware and software requirements; what was already in place and what needed to be acquired; and who was responsible for contacting other necessary groups.

\section{VENDOR SELECTION}

During the vendor selection phase I was surprised to discover that while I thought I had communicated clearly with both vendors and in our Request for Proposal, their responses indicated otherwise. For instance, the necessity to interface with the mainframe computer had been discussed from the beginning, but one of the vendors who had previously indicated this could be done, came back with a response that it could be done only with modification to an in-stock item. He could not give me a cost estimate or estimated delivery date. I also learned that although I had received their responses, I didn't have to accept them as is .- I could request clarification, explanation, and additional details. In all fairness to the bidders, we needed to be sure we understood their proposals so that we could evaluate them fairly prior to making our final decision.

Having the preplanned acceptance criteria was a big help. It eliminated the uncertainty about whether the vendors could meet our major requirements.

Finally, although the purchase specifications should spell out any conditions regarding the handling of software licensing agreements, it is a good idea to find out from your buyer what your 
responsibilities are if you are presented with licensing agreements. These are normally signed by authorized individuals.

\section{SYSTEM DESIGN}

Good communication and coordination between the vendor and the customer (me) proved to be very valuable. Meeting as soon as possible after the vendor selection to get all known facts and needs out in the open was also important. We thought we had involved the primary "players" who would be involved or affected, but in retrospect I think we should have included someone from the computer communications group. Having individuals designated as the primary contacts in the various fields of expertise helped immensely in knowing who to go to for information. This was especially important because our vendor was over 200 miles away. It also helped to establish communication between the vendor and the computer staff, enabling them to talk directly to each other regarding technical concerns, while also keeping me informed of such conversations.

\section{SYSTEM IMPLEMENTATION AND TESTING}

Implementing a leading-edge technology was a learning experience for all parties involved -- the vendor, the computer staff, and the end users. Because implementation involved the physical set-up of the equipment and making the necessary system connections, it took a major part of one week, which the vendor had allotted for both set-up and training.

In our case, the inability to coordinate a capital equipment purchase (the LOD) with the design and implementation of the new database proved to be a problem. Because the capital equipment needed to be purchased by a certain date, it arrived before the implementation of the database. Because we needed to interface with the mainframe for indexing validation, we could only validate against the test database, which was only a portion of the real database. This delayed scanning and indexing of records, creating a backlog. It also meant we could not adequately test or operate the electronic transaction portion of the new database. If you have a stand-alone 
system, the interfacing with a mainframe computer will not be a problem for you. In our case we underestimated the effect of incorporating the LOD system into the new database and the amcunt of interaction needed with and between the computer groups.

\section{ACCEPTANCE TESTING}

Like the lesson learned during the testing of the system design, acceptance testing by the customer would have been far more effective if the acquisition of the imaging system had been coordinated with the implementation of the new database and inc. 1ded as part of the overall plan.

In retrospect, I learned that system specifications may have had requirements for specific items that seemed very important at the time I wrote them. However, after working with the new system during the acceptance testing period, I discovered that some requirements were not as important as I had originally thought. Individual applications will dictate the importance of everything specified. For example, we required that a certain number of documents be able to feed through the automatic document feeder during the scanning process. However, due to the variety and condition of the documents we receive, this is not always possible. Some of our documents are on thinner paper that tends to curl. Others have been torn off of a pad of forms and glue from the tablet binding sticks to the top of the form, causing non-uniform scanning. These documents have to be handled differently than the rest. Even though we tried to anticipate all the questions that might arise, there was always something we had not thought of. I would recommend being reasonable in reviewing vendor capabilities against original specifications prior to final acceptance.

One big lesson learned involved the backlog of records. Because we normally kept our hard-copy records for one year before microfilming, we had one year's worth of records on the shelf in payroll number order. I had the impression that having the records in order would greatly enhance the process of scanning them into the system. However, sequencing them by payroll number did not help at all. Document type, not order, is significant when it comes to scanning 
them on the imaging system. Because each person's records contain numerous document types, they are being resorted by document type. This ensure that documents of certain sizes and types go through the scanner easier and makes indexing faster because we enter document type as an indexing criterion. Because they are in an order that can be easily located, we have left the bulk of the 1992 records on the shelf. The 1993 records are put in document type order as they come in the door and are scanned daily.

Another big lesson learned was that no matter how much we thought we knew operations would change, it was difficult to predict the effect of the changes. There was always something we hadn't thought of, or some unexplainable event that occurred and took several troubleshooting "experts" to resolve while work was stacking up -- for instance, the clerical staff had not worked in a Windows environment. The many screens to move through and the use of a mouse was a big adjustment. They adjusted quickly to the system, but found many of the screens either unnecessary or not efficiently designed. It took some use of the system for these deficiencies to be identified. There were also mounting delays and frustration when the communication with the mainframe was not working properly. This was not an easy problem to diagnose at first, but improvements have been made in this area. Also, there are invariably trade-offs between the pros and cons of old and new systems, such as with our change to indexing every document, where we used to index sets of documents. It may take much longer to index records under the new system, but retrieval and response time is almost instantaneous.

\section{CONCLUSION}

In conclusion, I think the most important recommendations I can make to anyone contemplating procurement of an LOD system are as follows:

- Be sure of what you want to accomplish; know and clearly define your objectives.

- Involve the system users in the entire process.

- Start small and grow as you achieve success. 
- Make no assumptions; spell everything out, especially in the specifications.

- Notify all involved parties up front so that everyone knows their roles and responsibilities.

- Coordinate your efforts with any outside groups whose supportive efforts will affect your goals.

- Have pre-planned acceptance criteria for vendor selection.

- Plan your system testing to cover all possible problems.

- Document final results of all tests. 


\section{REFERENCES}

Williams, R. F. 1984. Legality of Microfilm. Cohasset Associates, Inc., Chicago, pp. 3-4R - 3-5R.

Williams, R. F. 1988. "Are Optically Stored Records Legal?" Administrative Management, April, p. 22. 

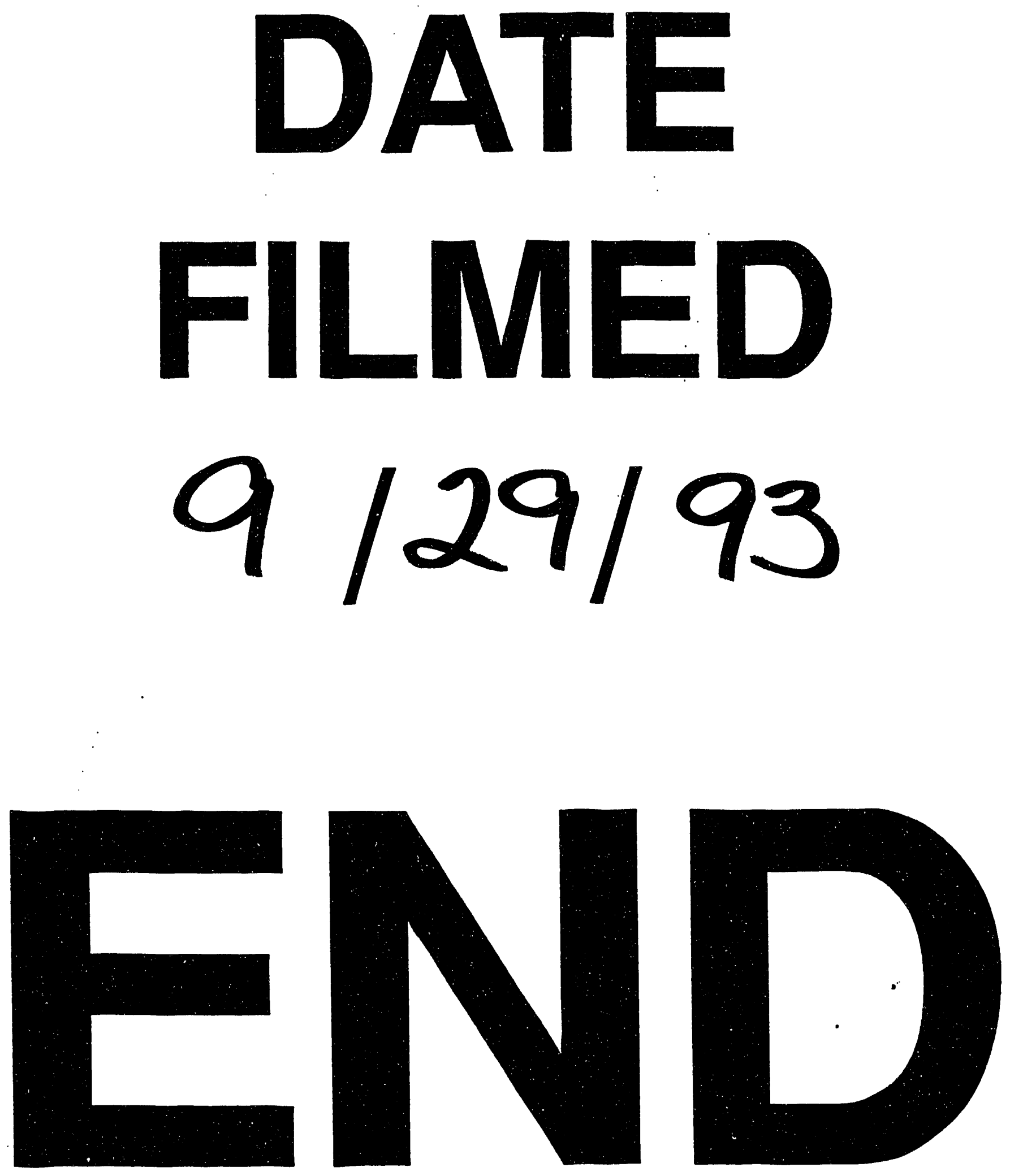
